\title{
Modifiye Edilmiş Pomza Kullanılarak Sulu Ortamlardan Adsorpsiyon Prosesi ile Arsenat (V) Giderimi
}

\author{
Bülent KIRKAN ${ }^{* 1}$ (1), Mustafa BEKAROĞLU² \\ ${ }^{1}$ Süleyman Demirel Üniversitesi, Su Enstitüsü, 32000, Isparta \\ ${ }^{2}$ Süleyman Demirel Üniversitesi, Fen Bilimleri Enstitüsü, Su Yönetimi Anabilim Dalı, 32000, ISPARTA
}

(Alınış / Received: 04.10.2018, Kabul / Accepted: 16.04.2019, Online Yayınlanma / Published Online: 30.08.2019)

\author{
Anahtar Kelimeler \\ Arsenat (V), \\ Katı faz ektraksiyonu, \\ Pomza, \\ Adsorpsiyon, \\ Demir oksit
}

\begin{abstract}
Özet: Bu çalışmada, adsorpsiyon yöntemi ile sulu ortamdan $\mathrm{As}(\mathrm{V})$ giderimi için ham ve yüzeyi modifiye edilmiş pomzanın etkinliği incelenmiștir. Granüler destek malzemesi olarak Isparta pomzası kullanılmış ve demir oksit ile kaplanmıştır. Katı sorbentlerinin yapı karakterizasyonunun belirlenmesi için FTIR, XRD ve BET yüzey alanı analizi yapılmış ve yüzey morfolojisinin gözlenmesi için SEM görüntüleri kullanılmıştır. HIP ve DOKIP katı sorbentleri kullanılarak sulu çözeltiden As(V) giderimini etkileyen çözelti $\mathrm{pH}^{\prime}$, , başlangıç As(V) konsantrasyonu, temas süresi, adsorbent dozu ve sıcaklık parametreleri incelenmiş ve optimum giderim koşulları tespit edilmiştir. DOKIP için maksimum As(V) giderimi ve adsorpsiyon kapasitesi

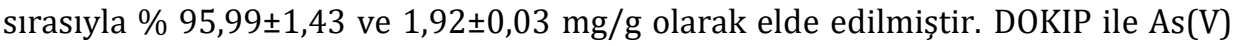
adsorpsiyonu için $\Delta \mathrm{H}, \Delta \mathrm{S}$ ve $\Delta \mathrm{G}$ termodinamik parametreleri hesaplanmış, adsorpsiyon prosesinin ekzotermik karakterli olduğu belirlenmiştir. Deneysel adsorpsiyon verilerinin Langmuir, Freundlich ve Dubinin-Radushkevich (D-R) izotermlerine uygunluğu incelenmiş ve adsorpsiyon verilerinin Langmuir modeline uyduğu belirlenmiştir. Yüksek adsorpsiyon kapasitelerine dayanarak, sulu çözeltilerden As (V)'in önderiștirilmesi ve gideriminde DOKIP sorbenti umut verici alternatif bir adsorban olarak önerilmiştir.
\end{abstract}

\section{Removal of Arsenate (V) by Adsorption Process from Aqueous Media Using Modified Pumice}

\section{Keywords}

Arsenate (V),

Solid phase extraction,

Pumice,

Adsorption,

Iron oxide

\begin{abstract}
In this study, the efficiency of row and surface modified pumice was investigated for As (V) removal from aqueous media by adsorption method. Isparta pumice is used as granular support material and coated with iron oxides. FTIR, XRD and BET surface area analysis were performed for determination of solid sorbents structure characterization and SEM images were used for observation of surface morphology. The impacts of $\mathrm{pH}$, initial $\mathrm{As}(\mathrm{V})$ concentration, contact time, adsorbent dose and temperature on $\mathrm{As}(\mathrm{V})$ removal were studied with using HIP and DOKIP as adsorbent and optimum removal conditions have been determined. The maximum As(V) removal and adsorption capacity of DOKIP1 were $95.99 \pm 1.43 \%$ and $1.92 \pm 0.03 \mathrm{mg} / \mathrm{g}$, respectively. The $\Delta H, \Delta \mathrm{G}$ and $\Delta \mathrm{S}$ thermodynamic parameters for $\mathrm{As}(\mathrm{V})$ adsorption of DOKIP are calculated and results showed that the adsorption process has exothermic character. The Langmuir, Freundlich and Dubinin-Radushkevich (D-R) isotherms were used to fit the equilibrium data. Langmuir model resulted in the best fit of the adsorption data. Based on high adsorption capacities, DOKIP sorbent has been proposed as a promising alternative adsorbent in the preconcentration and removal of As (V) from aqueous solutions.
\end{abstract}

\section{Giriş}

Dünya nüfusunun hızla artıyor olması ile birlikte endüstriyelleșmenin olması, tüm dünyada olduğu gibi ülkemizde de güvenli ve yeterli miktarda içme suyuna ulaşılmasında sıkıntılar yaşanmasına yol açmaktadır. Dünya genelinde olduğu gibi ülkemizde de su kaynaklarının kisitlı olmasının yanında su kalitesinde meydana gelen ciddi bozulmalar insan ve diğer canlıların sağlığını tehdit altına sokmaktadır. İçme sularında bulunan en tehlikeli kirleticiler 
arasında yer alan arsenik, kimyasal bileşimi ve maruziyet durumuna göre deri ve kas hastalıkları, kronik öksürük, akciğer, mesane ve deri kanserleri gibi sağlık sorunları ortaya çıkabilmektedir. Arseniğin toksisitesi bağlanma şekline bağlıdır ve inorganik arsenik türleri organik arsenik türlerine göre daha toksiktir [1]. As(III) indirgeyici koşullar altında baskın formken As(V) genellikle yükseltgeyici koşullarda kararlı formdur. Arsenik bileşiklerin toksisiteleri arsenik hidrit $\left(\mathrm{AsH}_{3}\right)>$ inorganik As $(3+)$ $>$ organik As $(3+)>$ inorganik As $(5+)>$ organik As $(5+)>$ As (0) sırasına göre azalmaktadır. Doğal sularda genel olarak inorganik formda arsenik(III) ve arsenik(V) olarak ifade edilen arsenit $\left(\mathrm{AsO}_{3}{ }^{3-}\right)$ ile arsenat $\left(\mathrm{AsO}_{4}{ }^{3-}\right)$ bulunur. Arseniğin üç değerlikli formu beş değerlikli formundan daha toksiktir ve çoğu teknikle sudan ayrımı zordur. Bu nedenle, As (III) çoğunlukla As(V)'e yükseltgenir ve As(V) adsorpsiyon, çöktürme ya da iyon değişimi gibi proseslerle ayrılır $[1,2,3,4]$.

Arseniğin zararlı etkileri ve artan sağlık sorunları nedeniyle içme sularındaki konsantrasyonu için maksimum değer bazı ülkelerde $50 \mu \mathrm{g} / \mathrm{L}^{\prime}$ den $10 \mu \mathrm{g}$ /L'ye düşürülmüştür [5]. Bu nedenle Dünya Sağlık Örgütü (WHO) tarafından izin verilen arsenik sınırı $10 \mu \mathrm{g} /$ L'dir. Ülkemizde de geçerli olan içme sularında izin verilen maksimum arsenik konsantrasyonu $10 \mu \mathrm{g} / \mathrm{L}^{\prime}$ dir. Yeraltı ve yerüstü su kaynaklarına doğal ve antropojenik kaynaklardan çözünerek gelebilen arseniğin en önemli kaynakları madencilik faaliyetleri, termik santrallerde fosil yakıtların yakılması, hayvancılıkta yem katkı maddesi olarak kullanımı ve arsenik içeren pestisitlerin tarımda kullanımı olarak sıralanmaktadır $[1,3,6]$.

Tüm dünyada ve ülkemizde kullanılan yerüstü ve yeraltı su kaynaklarında yönetmeliklerde izin verilen sınır değerlerin üzerinde arsenik tespit edilmesi durumunda, arsenik giderimi su kaynaklarının kullanımı açısından büyük önem taşımaktadır. Bu nedenle, su kaynaklarında mevcut hem organik hem de inorganik arsenik türlerinin uzaklaştırılması zorunlu olup, ucuz ve kolay işletilebilen yöntemlerin geliştirilmesi gerekmektedir. Çöktürme, membran filitrasyon, adsorpsiyon, anyon değiştirici reçineler gibi birçok metot arsenik giderimi için kullanılmaktadır $[2,7,8]$. Kullanılmakta olan bu uygulamaların yüksek maliyet, atık oluşumu, yüksek enerji gereksinimi ve uzaklaștırmayla ilgili problemler nedeniyle kullanımları sınırlıdır [9]. Su ortamında mevcut arseniğin giderilmesinde en çok uygulanan metotlardan biri de farklı sorbentlerin kullanılması ile gerçekleştirilen adsorpsiyon prosesidir. Adsorpsiyon teknolojisi basit, güvenilir, çevreyle uyumlu, etkin ve düşük maliyetli olması nedeniyle atık sulardan arsenik ayrımında çok ümit vaat eden bir tekniktir. Aktif karbon, aktif alümin, demir, demir bileșikleri, kum, silika, kömür, kırmızı çamur, balçık, mantar ve organik polimerler arsenik giderimi için adsorpsiyon prosesinde kullanılan başlıca sorbentlerdir $[2,8,10,11]$.
Bu çalışmada adsorbent olarak ham ve yüzeyi demir oksit ile modifiye edilmiş Isparta pomzası katı adsorbanları kullanılarak sulu ortamdan As(V) iyonlarının giderimi batch yöntemi ile yapılan deneysel çalışmalar ile incelenmiştir. Modifiye edilen pomza örneklerinin yapısı FTIR, XRD, BET yüzey alanı ve SEM görüntüleri teknikleri kullanılarak karakterize edilmiştir. Adsorpsiyona önemli olan çözelti pH'ı, başlangıç As(V) konsantrasyonu, temas süresi, adsorbent dozu ve sıcaklık parametrelerinin etkileri incelenmiştir. DOKIP adsorbenti ile As(V) adsorpsiyonu için termodinamik parametreleri hesaplanmış ve elde edilen deneysel verilerin Langmuir, Freundlich ve D-R adsorpsiyon izoterm modelleri ile uyumluluğu da araştırılmıştır.

\section{Materyal ve Metot}

\subsection{Kullanılan adsorban ve kimyasal maddeler}

Bu çalışmada Süleyman Demirel Üniversitesi Pomza Araştırma ve Uygulama Merkezi'nden sağlanmış olan Isparta pomzası kullanılmıştır. Ham Isparta Pomzası (HIP) öğütülerek elek sistemi ile farklı partikül büyüklüklerine göre ayrılmış ve kaplama işlemi için en büyük yüzey alanına sahip olan $<63 \mu \mathrm{m}$ partikül büyüklüklerine sahip ham pomza elde edilmiştir. Çalışmada kullanılan tüm kimyasal reaktifler analitik saflıkta olup Merck veya Sigma-Aldrich firmalarından temin edilmiștir. Çalıșmada deiyonize bidistile su kullanılmıştır. As(V) giderim çalışmalarında, 1000 $\mathrm{mg} / \mathrm{L}$ 'lik ana stok çözeltisi $\mathrm{HAsNa}_{2} \mathrm{O}_{4} .7 \mathrm{H}_{2} \mathrm{O}$ (Merck) tuzunun bidistile saf suda çözünmesiyle hazırlanmış ve günlük çalışma çözeltileri ana stok çözeltiden seyreltilerek hazırlanmıştır. As(V) iyonunun adsorpsiyon çalışmalarında çözeltilerin $\mathrm{pH}$ ayarlamaları 0,01 $\mathrm{M}$ nitrik asit $\left(\mathrm{HNO}_{3}\right)$ ve sodyum hidroksit $(\mathrm{NaOH})$ çözeltileriyle yapılmıştır. pH metre tampon çözeltiler ( $\mathrm{pH} 4$ ve 7) kullanılarak kalibre edilmiştir. Her deneysel çalışmada kör (blank) örnek kullanılmıştır. As(V) iyonlarının spektrofotometrik analizi için sülfürik asit $\left(\mathrm{H}_{2} \mathrm{SO}_{4}\right)$, potasyum antimon(III) oksit tartarat trihidrat $\left(\mathrm{K}_{2}(\mathrm{SbO})_{2} \mathrm{C}_{8} \mathrm{H}_{4} \mathrm{O}_{10} .3 \mathrm{H}_{2} \mathrm{O}\right)$, amonyum hepta molibdat tetra hidrat $\left(\left(\mathrm{NH}_{4}\right)_{6} \mathrm{Mo}_{7} \mathrm{O}_{24} .4 \mathrm{H}_{2} \mathrm{O}\right)$ ve askorbik asit kullanılmıştır.

\subsection{Adsorban hazırlanışı}

Pomza numunesi, analitik saflıta $\mathrm{FeCl}_{3} .6 \mathrm{H}_{2} \mathrm{O}$ kullanılarak demirle kaplanmıştır. Kaplamada Lai vd (2000)[12] ve Lai ve Chen (2001)[13] tarafından belirtilen metot bazı modifikasyonlar yapılarak kullanılmıştır [14]. Pomza önce $1 \mathrm{M}$ HCl asit çözeltisinde $\mathrm{pH} \quad 1$ 'de oda sicaklığında 24 saat bekletilmiştir, ultra saf su ile birkaç kez yıkanmış ve $103^{\circ} \mathrm{C}$ de 36 saat kurutulmuştur. Kurutulan yaklaşık 200 gr pomza numunesi 1 litrelik ısıya dayanıklı cam beherlere alınarak tüm pomza numunesi çözelti içerisinde kalıncaya kadar 0,5 M Fe (III) stok çözeltisi ilave edilmiştir. Çözelti sürekli olarak karıştırılarak, pH değeri 9,5 olana kadar damla damla $3 \mathrm{M} \mathrm{NaOH}$ 
eklenmiştir. Çözeltinin pH ayarlaması yapıldıktan sonra, karıștırma işlemine $30 \mathrm{dk}$ süre ile devam edilmiştir. Karıșım $50^{\circ} \mathrm{C}$ 'de ilk 50 saatinde karıștırma yapmak suretiyle toplam 100 saat kurutulmuştur. Daha sonra kurutulan karışım, yıkama suyundaki oluşan renk ve bulanıklık $(<0,1$ NTU) giderilene kadar ultra saf su ile yıkanmıştır. Son aşamada ise pomza numunesi içeriğinde mevcut nem uzaklaştırılıp sabit tartıma gelene kadar $80^{\circ} \mathrm{C}^{\prime}$ de 24 saat ve $50^{\circ} \mathrm{C}^{\prime}$ de 72 saat kurutulmuştur.

Partikül büyüklüğü $<63 \mu \mathrm{m}$ olan ham pomzanın modifikasyonu ile oluşan adsorbente DOKIP (Demir Oksit Kaplı Isparta Pomzası) kısaltması ile ifade edilmiştir.

\subsection{Kullanılan cihazlar}

Çalışmada, çözeltide mevcut As(V) derişimleri photoLab 6100 VIS model UV-Vis spektrofotometre ile ölçülmüştür. Batch yöntemi ile gerçekleştirilen adsorpsiyon çalışmaları, Wisd Wise Shake SHO-1P ve Gallenkamp CFC marka sicaklık ayarlı inkübatör çalkalayıcı ile gerçekleştirilmiştir. pH değerlerinin ölçümleri için Jenco marka 6173 model pH metre kullanılmıştır. FTIR spektrumları Thermo-Scientific, Nicolet IS10-ATR model spektrofotometrede alınmıştır. Sentezlenen katı fazların yüzey alanları Quantachrome Corporation, Autosorb-6 model cihaz ile ölçülmüș ve yüzey karakterizasyonu JEOL marka JSM-7600F model SEM cihazı ile görüntülenmiştir. Üretilen katı sorbentlerin XRD analizi Rigaku UltimaIV model cihaz ile yaptırılmıştır.

\subsection{As(V) analiz yöntemi}

Batch yöntemi ile deneysel çalışmalar sonrasında çözeltide kalan As(V) miktarının belirlenmesi UV-vis spektrometresi yöntemi [15] ile belirlenmiştir. Bu yöntem için ilk önce As(V) belirlenmesi için gerekli olan reaktif, $50 \mathrm{~mL} \mathrm{2,5} \mathrm{M}$ sülfürik asit $\left(\mathrm{H}_{2} \mathrm{SO}_{4}\right), 5 \mathrm{~mL}$ $\% 0,45$ potasyum antimon(III) oksit tartarat tri hidrat $\left(\mathrm{K}_{2}(\mathrm{SbO})_{2} \mathrm{C}_{8} \mathrm{H}_{4} \mathrm{O}_{10} .3 \mathrm{H}_{2} \mathrm{O}\right), 15 \mathrm{~mL} \% 5$ amonyum hepta molibdat tetra hidrat $\left(\left(\mathrm{NH}_{4}\right)_{6} \mathrm{Mo}_{7} \mathrm{O}_{24} .4 \mathrm{H}_{2} \mathrm{O}\right)$ ve $30 \mathrm{~mL}$ $\% 2,5$ askorbik asit çözeltilerinin karışımıyla hazırlanmıştır. Daha sonra As(V) miktarı belirlenecek örnek çözeltiden $2 \mathrm{~mL}$ alınarak üzerine 1,6 mL reaktif çözeltisi ve 6,4 mL saf su ilave edilerek hazırlanmış olan çözelti 30 dakika bekletilmiş ve son olarak elde edilen çözeltide UV-vis cihazında $880 \mathrm{~nm}$ dalga boyunda okuma yapılmıştır.

2.5. Batch yöntemi ile adsorpsiyon deneyleri, termodinamik parametreler ve adsorpsiyon izotermleri

Sulu çözeltiden As(V) giderimi için $<63 \mu \mathrm{m}$ partikül büyüklügüne sahip olan ham pomza ve bu pomza numunesine demir kaplanmış Isparta pomzası kullanılmıştır. HIP ve DOKIP katı faz adsorbanları üzerine As(V) alım denemeleri batch yöntemi kullanılarak çalkalayıcı ile gerçekleştirilmiştir. Farklı başlangıç konsantrasyonu ve pH'lardaki $\mathrm{As}(\mathrm{V})$ çözeltileri farklı süre, sıcaklık değişkenlerinde sabit çalkalama hızında katı faz adsorbantlar ile temas ettirilmiştir. Adsorpsiyon işleminin tamamlanması sonrasında katı faz adsorbant ve çözeltiler adi filtre kağıdı ile ayrılmış çözeltide kalan As(V) miktarı UVvisible spektrofotometrik olarak belirlenmiştir. Tüm denemeler en az üç paralel çalışma olarak yapılmış olup elde edilen sonuçların ortalaması kullanılmıştır. Adsorplanan As(V) miktarları başlangıç ve dengedeki konsantrasyon farkından hesaplanarak, $1 \mathrm{~g}$ adsorban üzerine adsorbe edilen $\mathrm{mg} \mathrm{As}(\mathrm{V})$ ifade eden adsorpsiyon kapasitesi ( $Q_{e}, \mathrm{mg} / \mathrm{g}$ ) ve adsorpsiyon (giderim) yüzdesi (\%) olarak hesaplanmıştır. Hesaplamalarda Denklem 1 ve 2 kullanılmıştır.

$$
\begin{gathered}
\mathrm{Q}_{\mathrm{e}}=\frac{\left(\mathrm{C}_{\mathrm{i}}-\mathrm{C}_{\mathrm{e}}\right) \mathrm{V}}{\mathrm{W}}(\mathrm{mg} / \mathrm{g}) \\
\text { \% Adsorpsiyon verimi }=\frac{\mathrm{m}_{\mathrm{i}}-\mathrm{m}_{\mathrm{e}}}{\mathrm{m}_{\mathrm{i}}} \times 100
\end{gathered}
$$

Burada; $C_{i}$ ve $C_{e}$ başlangıç ve dengedeki $\operatorname{As}(V)$ konsantrasyonu (mg/L), $\mathrm{m}_{\mathrm{i}}$ başlangıçta yüklenen As(V) miktarını ( $\mu \mathrm{g}), \mathrm{m}_{\mathrm{e}}$ adsorpsiyon sonrasinda çözeltide kalan As(V) miktarını ( $\mu \mathrm{g}), \mathrm{V}$ çözelti hacmini (mL), W adsorban miktarını (g) göstermektedir. As(V) iyonlarının DOKIP sorbenti üzerine adsorpsiyonunda adsorpsiyon entalpisi $(\Delta \mathrm{H})$, serbest enerji değişimi $(\Delta \mathrm{G})$ ve entropi değişimi $(\Delta \mathrm{S})$ gibi termodinamik parametrelerde incelenmiştir. Termodinamikte,

$$
\Delta G=-R T \operatorname{In} K_{C}
$$

denklemi aşağıdaki gibi yazılabilir;

$$
K_{C}=e^{-\Delta G / R T}
$$

$\mathrm{K}_{\mathrm{c}}$ denge sabiti Denklem 5'de verilmiştir.

$$
K_{c}=\frac{C_{A}}{C_{S}}
$$

Burada; $\mathrm{C}_{\mathrm{A}}$, dengede çözeltiden adsorban üzerine adsorplanan iyon miktarı (mg/L) $\mathrm{C}_{S}$, çözeltide kalan iyon miktarını ifade etmektedir. Yine termodinamikte serbest enerjinin $(\Delta \mathrm{G})$, entalpi $(\Delta \mathrm{H})$ ve entropi $(\Delta \mathrm{S})$ değișimi ile sıcaklığa bağımlılığı;

$$
\Delta G=\Delta H-T \Delta S
$$

şeklinde verilmiştir. Buradan;

$$
K_{C}=e^{-\frac{\Delta H-T \Delta S}{R T}}
$$

eșitliği elde edilir. Her iki tarafın In logaritması alınırsa;

$$
\text { In } K_{C}=\frac{\Delta S}{R}-\frac{\Delta H}{R T}
$$

elde edilir. 
DOKIP üzerine As(V) adsorpsiyonu için 1/T'ye karşı $\operatorname{lnK}_{c}$ değerleri grafiğe geçirilmiş, adsorpsiyonun $\Delta \mathrm{H}$ ve $\Delta \mathrm{S}$ değerleri hesaplanmıştır.

DOKIP sorbenti kullanilarak 0,2-8,0 $\mathrm{mg} / \mathrm{L}$ konsantrasyon aralığında, optimum koşullarda sulu çözeltilerden As(V) adsorpsiyonunda elde edilen deneysel verilerinin Langmuir, Freundlich ve D-R izotermlerine uygunluğu incelenmiștir.

\section{Bulgular}

\subsection{FT-IR analizleri}

HIP ve DOKIP adsorbenlerinin karakterizasyonu için yapılan FTIR analizleri sonucunda elde edilen spektrumlar Şekil 1'de verilmiştir. IR spektroskopisi adsorbentlerin karakterize edilmesinde kullanışlı olan bir yöntemdir. IR spektrumları incelendiğinde öncelikle 3460-3480 $\mathrm{cm}^{-1}$ bölgesinde adsorbentlerin yapısında bulunma ihtimali olan su molekülllerinden kaynaklanan yayvan piklerin şiddetinin az olduğu görülmektedir. Bu durum adsorbentlerin iç yapısında su moleküllerinin ihmal edilebilecek kadar az olduğunu göstermektedir. HIP ve DOKIP adsorbentlerinin spektrumlarında 980 ve $710 \mathrm{~cm}^{-1}$ bölgesinde gözlenen pikler karșılaștırıldığında demir oksit kaplama işlemi sonrasında bu bölgedeki piklerde kaymalar olduğu gözlenmiştir. $\mathrm{Bu}$ kaymaların pomza yüzeyine demir oksit kaplanması öncesinde yüzeyde bulunan fonksiyonel gruplar ile demir atomu arasında oluşan bağlanma sonrasında oluştuğu düşünülmektedir. Bu sonuçlara göre pomza yüzeyine demir oksit kaplanma işleminin başarılı bir şekilde gerçekleştiği görülmektedir.

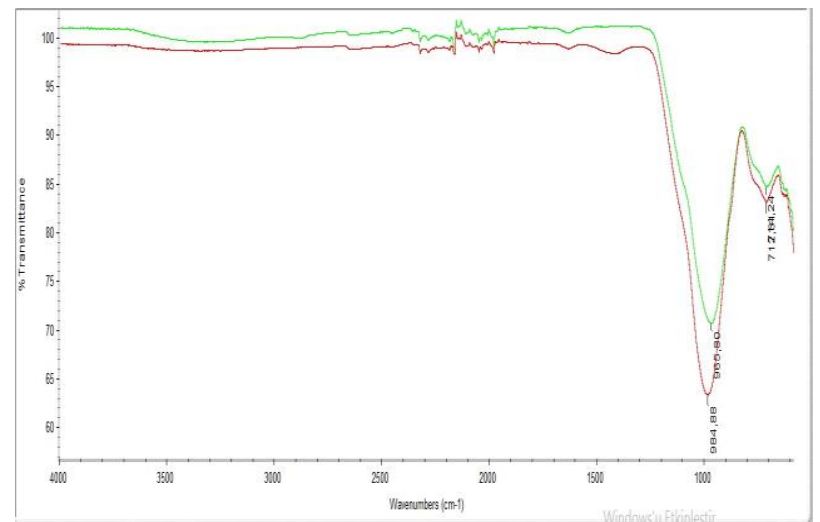

Şekil 1. HIP (kırmızı) ve DOKIP (yeşil)'nın FTIR spektrumu

\subsection{XRD analizleri}

DOKIP adsorbent örnekleri, koyu kırmızı renkli çökeltiler vermiş olup, çözünmeyen oksitler şeklinde demir varlığına işaret etmektedir. HIP ve DOKIP için elde edilen XRD spektrumları, Şekil 2 ve 3'de verilmiştir. HIP ve DOKIP adsorbentlerinin XRD spektrumları karşılaştırıldığında mevcut kristal yapılar büyük ölçüde benzerlik göstermesine rağmen bazı farklılıkların olduğu da gözlenmiştir. XRD spektrumlarında gözlenen faklılıkların HIP adsorbentinin modifikasyonu sonrasında gotit (goethite) $(\alpha-\mathrm{FeOOH})$ oluşumu nedeniyle gerçekleștiği düşünülmektedir $[16,17]$. Gözlenmiş olan bu farklılıklar HIP üzerine demir oksit kaplama işleminin gerçekleştiğini göstermektedir.

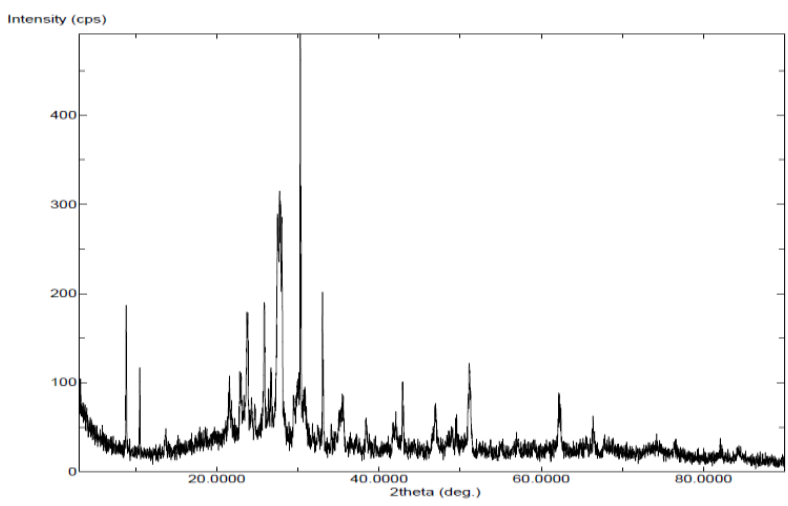

Şekil 2. HIP XRD spektrumu

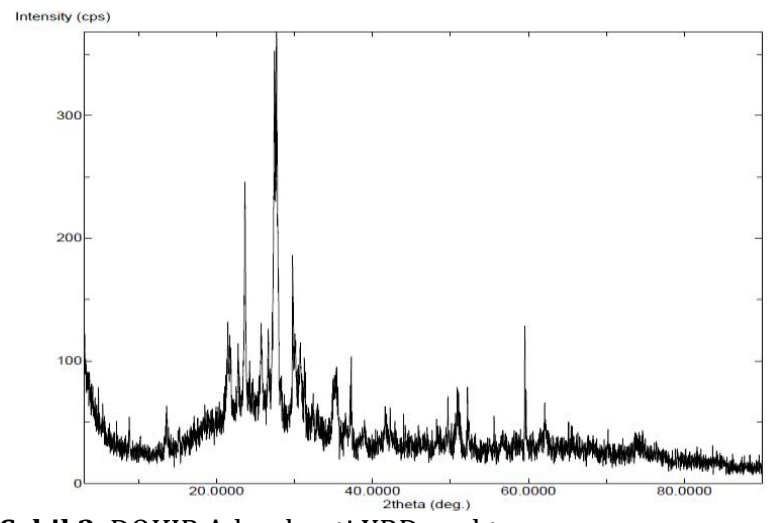

Şekil 3. DOKIP Adsorbenti XRD spektrumu

\subsection{BET yüzey alanı}

HIP ve DOKIP katı sorbentlerinin spesifik yüzey alanları BET yüzey analizi yöntemi kullanılarak belirlenmiştir. DOKIP adsorbentlinin elde edilen BET yüzey alanı analizi sonuçlarından pomza yüzeyine demir oksit kaplanma işleminin gerçekleştiği söylenebilmektedir. HIP ve DOKIP örneklerinin spesifik yüzey alanları sırasıyla 2,28 ve $13,58 \mathrm{~m}^{2} \mathrm{~g}^{-1}$ olarak elde edilmiştir. Elde edilen sonuçlara göre HIP örneklerinin spesifik yüzey alanlarının demir oksit ile kaplandıktan sonra arttığını ve bu yüzey alanlarına sahip adsorbentlerin sulu çözeltiden $\mathrm{As}(\mathrm{V})$ gideriminde HIP örneklerine göre daha etkin olabileceği görülmektedir. Literatürde demir götit ve hidritin küçük partiküllerinin yüzey alanları sırasıyla $60-120$ ve $200-500 \mathrm{~m}^{2} / \mathrm{g}$ Fe olarak belirtilmiştir [18]. $\mathrm{Bu}$ nedenle daha fazla yüzey alanına sahip demir oksitlerin pomza yüzeyine kaplanması sonucu destek malzemenin yüzey alanının artması literatürle tutarlılık göstermektedir.

\subsection{SEM analizleri}

Katı sorbentlerin SEM görüntülerinden modifikasyonun gerçekleşip gerçekleşmediği hakkında kesin bir sonuca varmak doğru olmamakla birlikte, modifikasyondan sonra HIP yüzeyindeki 
değişiklikler olduğu görülmektedir. Bu durum diğer karakterizasyon yöntemlerinden elde edilen bulgulara bir destek oluşturmaktadır. Şekil 4'de, HIP ve DOKIP adsorbentlerine ait SEM görüntüleri (250x büyütülmüş) verilmiştir. HIP SEM görüntüleri, demir ile kaplanmış pomza görüntülerine göre belirgin olarak daha düzgün yüzeylere sahipken, DOKIP adsorbentinin SEM görüntüleri yüzeyleri demir oksit ile kaplanması nedeniyle daha pürüzlü bir yüzeye sahip olduğu görülmektedir [19]. HIP adsorbentinin gözenek morfolojisi, homojen yapıdan heterojen yapıya değişim göstermiștir.

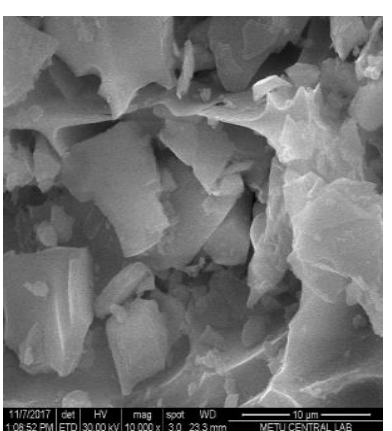

HIP

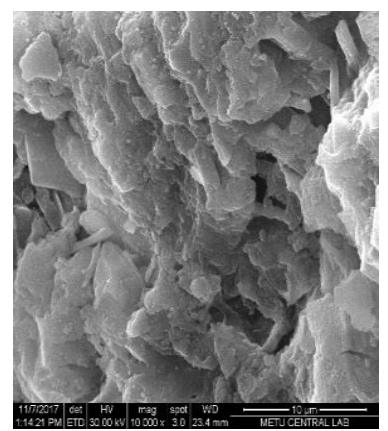

DOKIP
Şekil 4. HIP ve DOKIP adsorbentleri için SEM görüntüleri

\subsection{Batch yöntemi ile As(V) adsorpsiyon deneyleri}

\subsection{1. pH etkisi}

Adsorpsiyon çalışmalarında giderimi yapılacak olan kirleticinin çözeltide bulunduğu kimyasal formları yönünden çözelti pH’ı önemli bir parametredir. $\mathrm{As}(\mathrm{V})$ adsorpsiyonunda $\mathrm{pH}$ etkisini incelemek üzere pH'ları 2,0 ile 9,0 arasında olacak şekilde ayarlanan, 1 mg/L'lik As(V) çözeltileri hazırlanmıştır. Bu çözeltilerden alınan 25 mL'lik kısımlar adsorbent dozu $2 \mathrm{~g} / \mathrm{L}$ alınarak (HIP ve DOKIP) $25^{\circ} \mathrm{C}^{\prime} \mathrm{de} 60 \mathrm{dk}$ süre ile $250 \mathrm{rpm}$ 'de çalkalanmıştır.

pH 2,00'de sulu ortamda arsenik iyonlarının moleküler arsenik asit $\left(\mathrm{H}_{3} \mathrm{AsO}_{4}\right)$ formunda bulunması, protonlanmış yüzeye sahip adsorbentin ilgisini azaltmaktadır. Bu nedenle bu pH değerinde adsorpsiyon verimi iki adsorbent içinde en düşük olarak belirlenmiştir. Çözetinin pH değeri 3,0 olduğunda adsorpsiyon veriminde artış gözlenmiştir. Adsorpsiyonda gözlenen bu artış pH 3,0 değerinde ortamda moleküler arsenik asit yanında anyonik $\mathrm{H}_{2} \mathrm{AsO}_{4}^{-}$iyonlarının yaklaşık \%85 oranında bulunmasından kaynaklandığı düşünülmektedir. Bunun yanında elektrostatik çekim kuvvetlerinden dolayı düşük pH değerlerinde protonlanmış yüzey gruplarının mevcut olması anyon formundaki türlerin adsorpsiyon verimini arttırmaktadır. Çözeltinin $\mathrm{pH}$ değeri 3,0'ten 9,0'a arttırıldığında ise $\mathrm{As}(\mathrm{V})$ adsorpsiyon verimi ve adsorpsiyon kapasitesinin azaldığı gözlenmiştir. Adsorpsiyon verimindeki bu azalmanın bazik bölgeye gidildikçe çözeltide mevcut $\mathrm{OH}^{-}$iyonlarının konsantrasyonunun artışından kaynaklandığı düşünülmektedir. Literatürde $\mathrm{pH} \mathrm{3,0}$ ve 4,0'te en yüksek $A s(V)$ adsorpsiyon verimlerinin gözlendiği çalışmalar mevcuttur [20,21,22,23,24].

Şekil 5'de görüldügü gibi HIP ve DOKIP sorbentleri ile As(V) adsorpsiyonunun maksimum gerçekleştiği optimum pH değerleri sirasıyla 4,0 ve 3,0 olarak belirlenmiş ve diğer parametrelerin incelenmesinde bu değer dikkate alınmıştır.

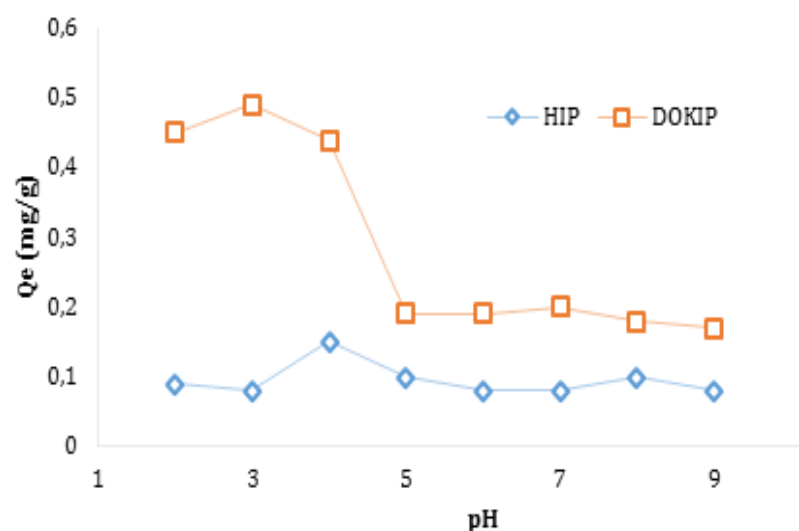

Şekil 5. HIP ve DOKIP adsorbentleri ile $\mathrm{As}(\mathrm{V})$ adsorpsiyonunda $\mathrm{pH}$ değişkenine göre $\mathrm{Qe}_{\mathrm{e}}$ değişimi

\subsubsection{Temas süresi etkisi}

Temas süresinin As(V) iyonlarının adsorpsiyonuna etkisi 5 ile 240 dakika süre aralıklarında incelenmiștir. As(V) çözeltileri HIP ve DOKIP için sırasıyla pH 4,0 ve 3,0 olacak şekilde 25 mL'lik 1 $\mathrm{mg} / \mathrm{L} \mathrm{As}(\mathrm{V})$ çözeltileri, $50 \mathrm{mg}$ sorbentler $(2 \mathrm{~g} / \mathrm{L})$ ile 25 ${ }^{\circ} \mathrm{C}$ 'de, $250 \mathrm{rpm}$ çalkalama hızında, farklı sürelerde çalkalanması ile gerçekleştirilmiştir. Temas süresinin değişmesiyle sorbentler üzerine çözeltiden $\mathrm{As}(\mathrm{V})$ adsorpsiyonunun değişimi Şekil 6'da verilmiştir.

Şekil 6'da görüldüğü gibi HIP adsorneti için $15^{\prime}$ 'inci dakikada en yüksek \%28,16'llk adsorpsiyon verimine ulaşılmış daha sonrasında aynı seviyelerde adsorpsiyon yüzdeleri elde edilmiş ve adsorpsiyon dengesinin kurulmuş olduğu 15 dakika optimum çalkalama süresi olarak belirlenmiştir.

DOKIP adsorbenti ile As(V) adsorpsiyonunda temas süresinin artmasıyla adsorpsiyon veriminin de arttığ gözlenmiştir. Şekil 6'da görüldüğü gibi 30'uncu dakikada en yüksek \%97,64'lük adsorpsiyon verimine ulaşılmış ve daha sonrasında adsorpsiyon veriminde denge oluşmuştur. DOKIP ile As(V) iyonlarının adsorpsiyonunda, adsorpsiyon dengesinin kurulduğu 30 dakika optimum çalkalama süresi olarak belirlenmiștir. 


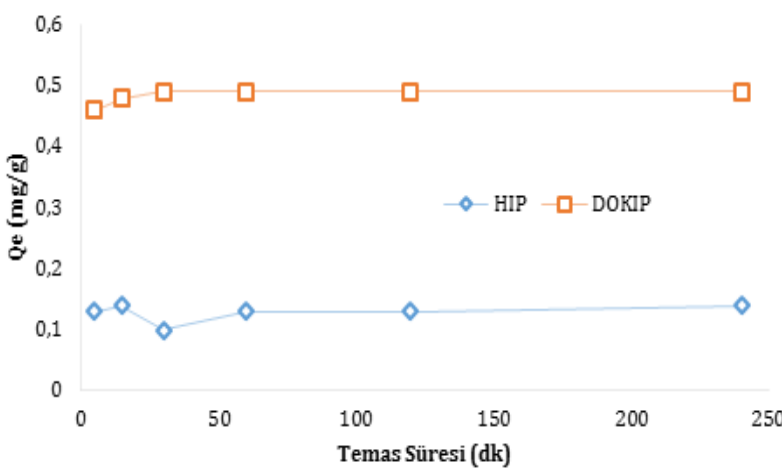

Şekil 6. Sorbentlere As(V) adsorpsiyonunda temas süresi etkisi

\subsubsection{Başlangıç As(V) konsantrasyonu etkisi}

Başlangıç As(V) konsantrasyonunun adsorpsiyon verimine etkisi 0,2 ile $8 \mathrm{mg} / \mathrm{L}$ aralığında incelenmiştir. HIP ve DOKIP için çözelti pH'ı sırasıyla 4,0 ve 3,0 olacak şekilde verilen konsantrasyon değerlerinde 25 mL'lik As(V) çözeltileri, $50 \mathrm{mg}$ sorbentler ile $25^{\circ} \mathrm{C}$ 'de, HIP ve DOKIP için sırasıyla 15 ve 30 dakika temas sürelerinde $250 \mathrm{rpm}$ çalkalama hızında çalışılmıştır.

Şekil 7'de görüldüğü gibi HIP ve DOKIP sorbentleri için maksimum adsorpsiyon verimi $1 \mathrm{mg} / \mathrm{L} \mathrm{As}(\mathrm{V})$ konsantrasyonunda elde edilmiștir. Ancak daha yüksek konsantrasyonlarda adsorpsiyon verimi azalırken, sorbent başına adsorplanan As(V) iyonu miktarının arttığı gözlenmiştir. Sorbent başına adsorplanan $\mathrm{As}(\mathrm{V})$ iyonu miktarının artışı $1 \mathrm{mg} / \mathrm{L}$ konsantrasyonundan sonra daha düşük artış göstermektedir. Bu artışın çözelti ortamında $\mathrm{As}(\mathrm{V})$ iyonlarının konsantrasyonla artması sonucu sorbent yüzeyinde tabakalaşma nedeniyle gerçekleștiği düşünülmektedir. Sulu ortamda mevcut As(V) iyonlarının maksimum giderim verimine göre optimum başlangıç As(V) konsantrasyonuna karar verilmiştir. Ayrıca bu yöntemin daha düşük As(V) konsantrasyona sahip gerçek örneklere uygulanması düşünüldüğü için, daha sonraki parametrelerin incelenmesinde maksimum adsorpsiyon verimlerinin elde edildiği HIP ve DOKIP için $1 \mathrm{mg} / \mathrm{L} \mathrm{As(V)}$ başlangıç konsantrasyonunda çalışılmasının uygun olacağı görüşüne varılmıştır.

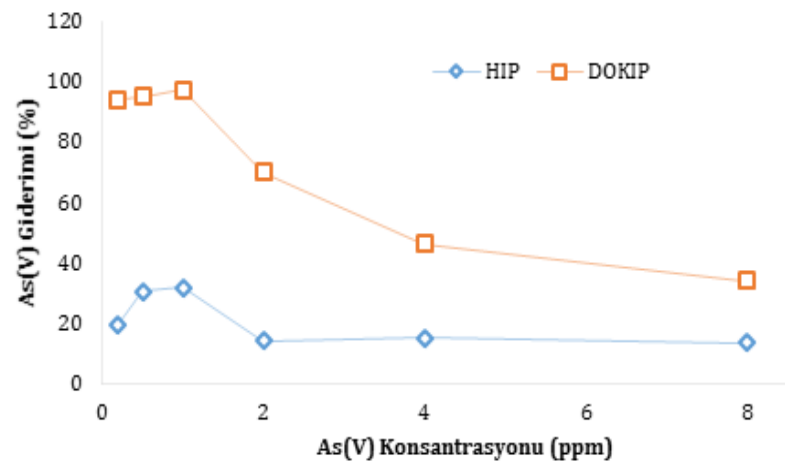

Şekil 7. Sorbentlere $\mathrm{As}(\mathrm{V})$ adsorpsiyonunda başlangıç $\mathrm{As}(\mathrm{V})$ konsantrasyonu etkisi

\subsubsection{Adsorban dozu etkisi}

Adsorpsiyonda en etkili parametrelerden biri de adsorbent miktarıdır. Bu parametrenin incelenmesi $25 \mathrm{~mL}$ sabit hacimde, adsorbent dozunun 0,25 ile 8 $\mathrm{g} / \mathrm{L}$ aralığında değiştirilmesiyle elde edilen sorbent miktarları için, $25{ }^{\circ} \mathrm{C}^{\prime}$ de; HIP ve DOKIP için $\mathrm{pH}$ sırasıyla 4,0 ve 3,0'de; $1 \mathrm{mg} / \mathrm{L} \mathrm{As(V)}$ içeren çözelti; HIP ve DOKIP sorbentleri için sirasıyla 15 ve 30 dakika temas süresi ile 250 rpm'de çalkalanarak gerçekleștirilmiştir.

Adsorbent dozu çalışmasında adsorpsiyon veriminin sabit kaldığı noktalarda adsorbent dozu artışı ile $Q_{e}$ değeri azalış göstermektedir. Bu nedenle Şekil 8'de görüldüğü gibi HIP ve DOKIP adsorbentleri için adsorpsiyon veriminin sabit kaldığı sırasıyla 2 ve 0,5 $\mathrm{g} / \mathrm{L}$ değerleri optimum adsorbent dozu olarak belirlenmiştir.

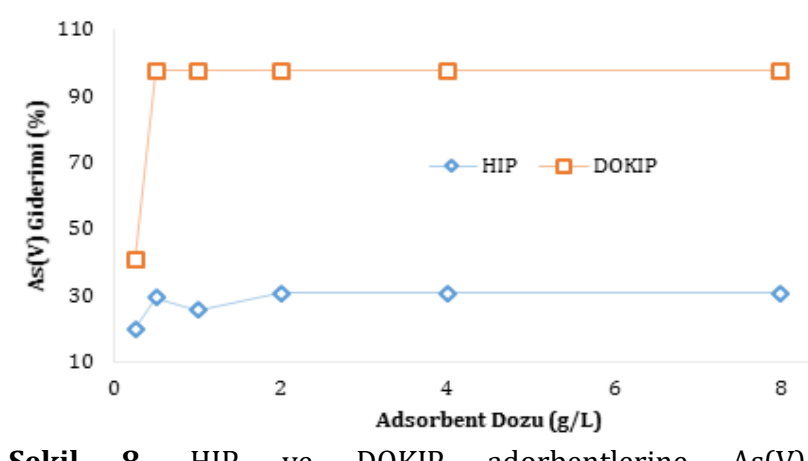

Sekil 8. HIP ve DOKIP adorbentlerine As(V) adsorpsiyonunda adsorbent dozu (g/L) etkisi

\subsubsection{Sicaklık etkisi}

As(V) adsorpsiyonunda ortam sicaklığ belirlenen optimum koşullarda, $250 \mathrm{rpm}$ çalkalama hızı ve $25-55^{\circ} \mathrm{C}$ sıcaklık aralığında, incelenmiștir.

HIP ve DOKIP adsorbentlerine As(V) adsorpsiyonuna sıcaklığın etkisi çalışmalarından elde edilen sonuçlar, Şekil 9'da verilmektedir. Şekil 9'da görüldüğü gibi sıcaklığın $55{ }^{\circ} \mathrm{C}^{\prime} y e$ arttırılmasıyla adsorpsiyon veriminde düşüş gözlenmiştir. HIP ve DOKIP adsorbentleri için en yüksek adsorpsiyon kapasitesinin gerçekleștiği $25{ }^{\circ} \mathrm{C}$ optimum çalışma sıcaklığı olarak belirlenmiștir. Bu sonuca göre DOKIP sorbenti ile $\mathrm{As}(\mathrm{V})$ adsorpsiyonunun ekzotermik karakterli olduğu görülmüștür.

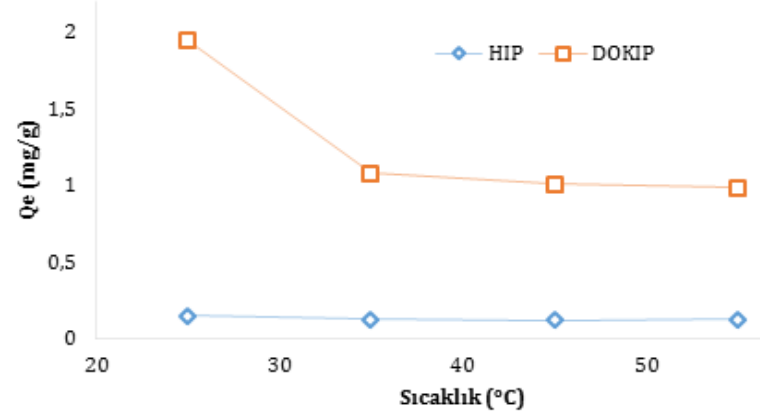

Şekil 9. Sorbentlere As(V) adsorpsiyonunda sıcaklık etkisi 


\subsection{DOKIP sorbentine As(V) Adsorpsiyonunda Termodinamik Özelliklerinin İncelenmesi}

Denklem 8 kullanılarak elde edilen Şekil 10'da verilmiş olan [In Kc] vs [1/T] grafiğinin kesim noktası ve eğiminden yararlanarak adsorpsiyon $\Delta \mathrm{H}$ ve $\Delta \mathrm{S}$ değerleri elde edilmiştir. Spesifik adsorpsiyonun $\Delta \mathrm{G}$ değeride, Denklem 6 kullanılarak hesaplanmıştır. DOKIP sorbenti ile As(V) adsorpsiyonundan hesaplanan $\Delta \mathrm{H}, \Delta \mathrm{S}$ ve $\Delta \mathrm{G}$ termodinamik parametre değerleri sırasıyla $-0,078 \mathrm{~kJ} / \mathrm{mol} . \mathrm{K},-0,173 \mathrm{~kJ} / \mathrm{mol} . \mathrm{K}$ ve $54,0 \mathrm{~kJ} / \mathrm{mol}$ olarak elde edilmiș ve Tablo 1'de verilmiştir. $\Delta H^{\prime}$ ın negatif değerde olması adsorpsiyonun ekzotermik karakterde olduğunu göstermektedir. Literatürde benzer negatif $\Delta \mathrm{H}$ değerine sahip çalışmalar mevcuttur [25,26,27]. Negatif $\Delta S$ değeri adsorpsiyon prosesi esnasında katı sıvı ara yüzeyinde $\mathrm{As}(\mathrm{V})$ iyonunun adsorpsiyonu sonucu moleküler harekette azalmayla ilişkilendirilir $[25,26]$. As(V) iyonlarının DOKIP sorbentine adsorpsiyonunda bulunan $-0,078 \mathrm{kj} / \mathrm{mol}^{\prime}$ lük düşük $\Delta \mathrm{H}$ değeri nedeniyle adsorpsiyonun fiziksel adsorpsiyon olduğu söylenebilir.

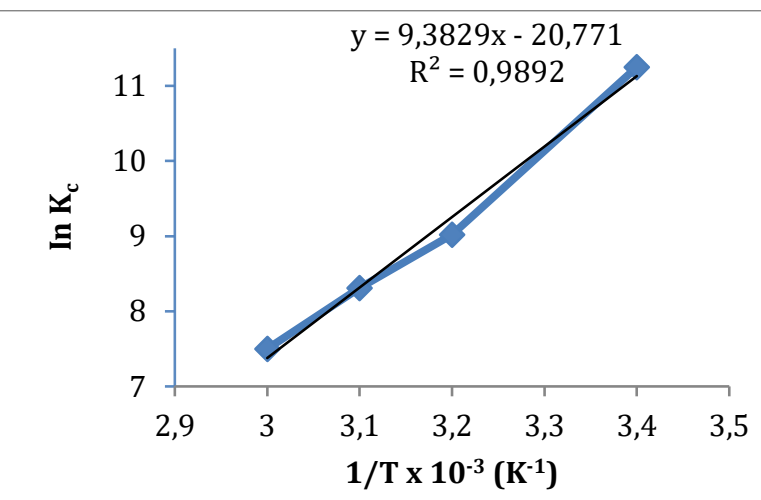

Sekil 10. As (V)'ın DOKIP sorbenti ile adsorpsiyonunda $\left[\operatorname{InK}_{c}\right]$ vs $[1 / \mathrm{T}]$ grafiğ $\mathrm{i}$

Tablo 1. As(V)'ın DOKIP sorbentine adsorpsiyonuna ait termodinamik parametreler

\begin{tabular}{|lllll|}
\hline $\begin{array}{l}\text { Adsorpsiyon } \\
\text { entalpisi }(\boldsymbol{\Delta H})\end{array}$ & \multicolumn{2}{l|}{$-78,01 \mathrm{~J} / \mathrm{mol} \mathrm{K}$} & & \\
\hline $\begin{array}{l}\text { Entropi değişimi } \\
(\boldsymbol{\Delta S})\end{array}$ & $-172,689 \mathrm{~J} / \mathrm{mol} \mathrm{K}$ & & \\
\hline Sıcaklık (K) & 298,15 & 308,15 & 318,15 & 328,15 \\
\hline $\begin{array}{l}\text { Serbest enerji } \\
\text { değişimi }\end{array}$ & 51,41 & 53,14 & 54,87 & 56,59 \\
$(\boldsymbol{\Delta G}) \mathbf{k J} / \mathbf{m o l}$ & & & & \\
\hline
\end{tabular}

\subsection{As(V) adsorpsiyon izoterm deneyleri}

\subsubsection{Langmuir adsorpsiyon izotermi}

Langmuir adsorpsiyon izoterm modeli, absorban yüzeyindeki belli sayıda aktif merkeze homojen doygun tek tabakalı adsorpsiyonu kabul eden ve belli adsorplanan konsantrasyonunda, yüzeyin doygunluğa eriștiğini varsayan teorik bir modeldir. Bu model, adsorpsiyon dengesinin dinamik olduğunu yani bir dt zamanı içinde adsorplanan madde miktarının, adsorban yüzeyinden ayrılan madde miktarına eşit olduğunu varsayar. Langmuir modeli [28] aşağıdaki denklemle ifade edilir;

$$
\frac{1}{Q_{e}}=\frac{1}{Q_{\max }}+\frac{1}{Q_{\max } K_{L}} \frac{1}{C_{e}}
$$

Burada $\mathrm{C}_{\mathrm{e}}$; denge konumunda çözeltide kalan adsorplanmamıș As(V) konsantrasyonunu (mg/L), Qe; dengede, birim kütledeki (g) adsorbentin adsorpladığı $\mathrm{As}(\mathrm{V})$ miktarını (mg) ifade ederken $\mathrm{Q}_{\max }$ $(\mathrm{mg} / \mathrm{g})$ ve $\mathrm{K}_{\mathrm{L}}(\mathrm{L} / \mathrm{mg})$ değerleri ise kapasite ve enerji ile ilişkili Langmuir sabitlerini göstermektedir. Denklem 9'a göre $\left[1 / \mathrm{Q}_{\mathrm{e}}\right]$ vs $\left[1 / \mathrm{C}_{\mathrm{e}}\right]$ grafiği Şekil 11 'de verilmiş ve grafiğin kesim noktası ve eğiminden yararlanarak $Q_{\max }$ değeri 4,74 mg/g ve $\mathrm{K}_{\mathrm{L}}$ değeri 3,98 $\mathrm{L} / \mathrm{mg}$ olarak hesaplanmış ve elde edilen bu sabitlerin değerleri, Tablo 2'de verilmiștir.

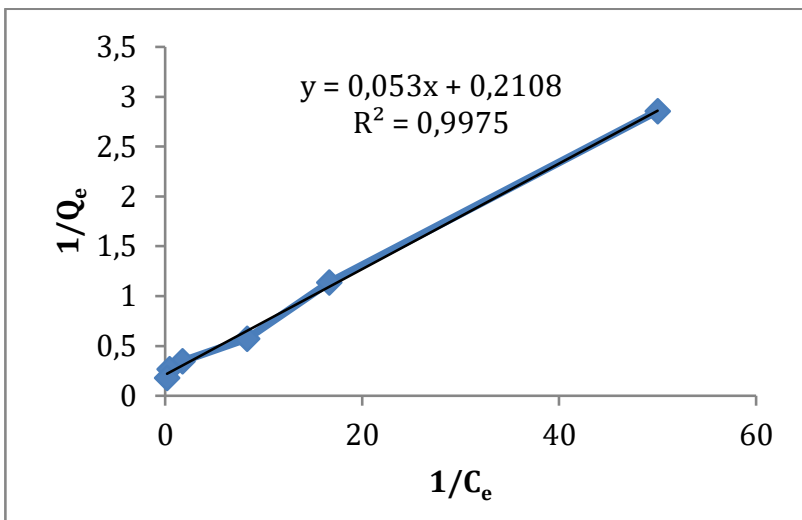

Şekil 11. As(V) DOKIP sorbenti üzerine adsorpsiyonu için Langmuir izotermi

\subsubsection{Freundlich adsorpsiyon izotermi}

Freundlich tarafından geliştirilen ve izotermal adsorpsiyonu belirten Freundlich izotermi ise heterojen yüzey enerjileri için özel bir durumu ifade eder. Genel olarak, Freundlich modeli adsorplanan maddenin konsantrasyonu arttıkça dengede adsorplanan miktarların arttığı heterojen yüzeylerdeki adsorpsiyonu ifade eden daha gerçekçi bir modeldir. Freundlich izoterm modeli [29] genel olarak;

$$
\log Q_{e}=\log K_{F}+\frac{1}{n} \log C_{e}
$$

şeklinde ifade edilmektedir. Denklemdeki $\mathrm{q}_{e}$ ve $\mathrm{C}_{\mathrm{e}}$ Langmuir modelindeki $Q_{e}$ ve Ce'ye eşdeğer olmaktadır. $K_{F}(\mathrm{mg} / \mathrm{g})$ kapasite ile ilgili Freundlich sabitini gösterirken, $1 / \mathrm{n}$ değeri heterojenite faktörü olup 0 ile 1 arasında bir değerdir. Heterojen yüzeylerde heterojenlik arttıkça $1 / \mathrm{n}$ değeri sıfıra yaklaşır. Denklem 10'a göre [log $\left.Q_{\mathrm{e}}\right]$ vs $\left[\log \mathrm{C}_{\mathrm{e}}\right]$ grafiği elde edilmiş ve Şekil 12'de verilmiştir. Şekil 12'de verilmiş olan grafiğin kesim noktası ve eğiminden yararlanarak $K_{F}$ değeri 3,01 mg/g ve $1 / \mathrm{n}$ değeri 0,45 olarak hesaplanmış ve elde edilen bu sabitlerin değerleri Tablo 2'de verilmiştir. 


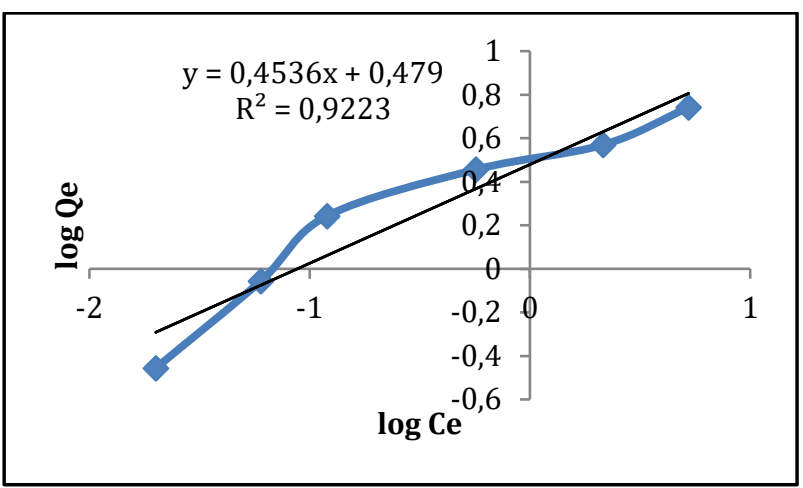

Şekil 12. As(V)'ın DOKIP sorbenti üzerine adsorpsiyonu için Freundlich izotermi

\subsubsection{Dubinin-Radushkevich (D-R) adsorpsiyon izotermi}

Adsorplanan fazın sıvı halde olduğu, diğer bir ifade ile adsorplanan sıvı faz buhar basıncinın aynı sıcaklıktaki saf sıvı faz buhar basıncına eşit olduğunu, sistem dengede iken 1 mol maddenin buhar fazından adsorplanmış faza tersinir olarak taşınmasındaki maksimum işin adsorpsiyon potansiyelinin $\varepsilon$ olarak tanımlandığı Polonyi izotermini esas almaktadır. D-R adsorpsiyon izoterminde adsorban mikrogözenek hacminin adsorpsiyon potansiyeli ile değișiminin Gauss dağılımına benzediğini ileri sürülerek, buhar fazından adsorpsiyonlarda $\varepsilon=\mathrm{RT} \ln \left[\mathrm{P}_{\mathrm{o}} / \mathrm{P}\right]$, çözelti fazından adsorpsiyonlarda ise $\varepsilon=R \ln \left[1+\left(1 / \mathrm{C}_{e}\right)\right]$ olarak alınır. Xm maksimum iyon değişim kapasitesi, $\beta$ adsorplanan maddeye özel bir sabit olmak üzere adsorpsiyon izoterm [30] denklemi aşağıda verilmiştir.

$$
C_{a d s}=X_{m} \exp \left(-\beta \varepsilon^{2}\right) \text { veya } \ln C_{a d s}=\ln X_{m}-\beta \cdot \varepsilon^{2}
$$

D-R adsorpsiyon izoterminin incelenmesinde adsorpsiyon bulguları kullanılarak hazırlanmış Denklem 11'e göre [ $\left.\varepsilon^{2}\right]$ vs [lnCads] değişim grafiği Şekil 13'de verilmiş ve grafiğin kesim noktasından yararlanarak $X_{\mathrm{m}}$ değeri $5,90 \mathrm{mg} / \mathrm{g}$ olarak hesaplanmıştır. Grafiğin eğiminden hesaplanan $\beta$ değeri kullanılarak adsorpsiyon enerjisi; $E=1 /(-2 \beta)^{1 / 2}$ denklemi yoluyla $0,11 \mathrm{~kJ} / \mathrm{mol}$ olarak hesaplanmış ve elde edilen bu sabitlerin değerleri Tablo 2'de verilmiştir. Dubinin-Radushkevich izoterm modeline göre; adsorbsiyonun serbest enerji değeri 8,0 $\mathrm{kJ} / \mathrm{mol}$ 'den küçük değerleri için adsorpsiyon fiziksel, 8-16 kJ/mol aralığında ise kimyasal iyon değişimi olarak gerçekleşmektedir $[25,31,32]$. Bu nedenle bu çalışmada elde edilen adsorpsiyon enerjisi değerine göre fiziksel bir adsorpsiyonun olduğu sonucuna varılmıştır.

Tablo 2'de görüldüğü gibi As(V) iyonlarının Langmuir, Freundlich ve D-R izoterm modellerindeki davranışlarının incelenmesinden $\mathrm{As}(\mathrm{V})$ iyonlarının DOKIP sorbentine adsorpsiyonunun Langmuir $\left(\mathrm{R}^{2}=0,998\right)$ izotermine uyduğu gözlenmiştir. Freundlich $\quad\left(\mathrm{R}^{2}=0,922\right)$ ve $\mathrm{D}-\mathrm{R} \quad\left(\mathrm{R}^{2}=0,831\right)$ izotermlerine $\mathrm{As}(\mathrm{V})$ iyonlarının DOKIP sorbentine adsorpsiyonunun uymadığı görülmektedir.

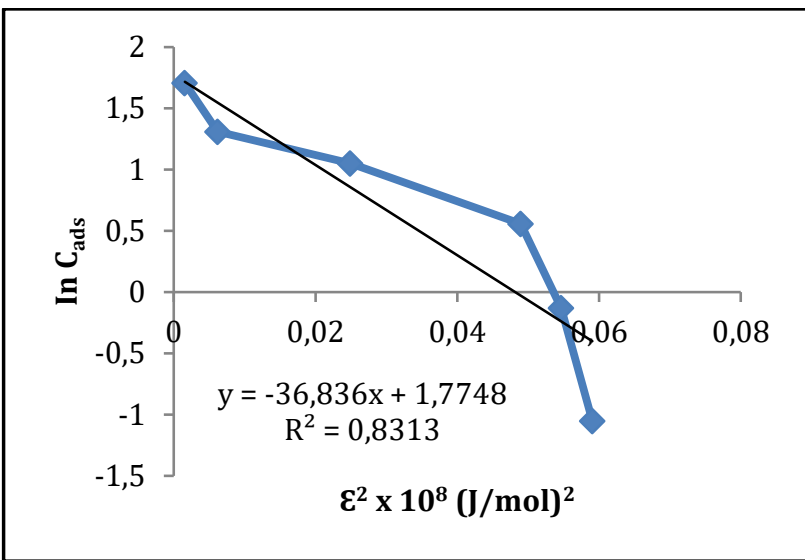

Şekil 13. As(V)'ın DOKIP sorbenti üzerine adsorpsiyonu için D-R izotermi

DOKIP sorbentine As(V) adsorpsiyonunun Langmuir izoterm eğrisine uygunluk göstermesinden, DOKIP yüzeyindeki belli sayıda aktif merkeze tek tabakalı dinamik bir adsorpsiyonun olduğu ve yüzeyin doygunluğa eriștiği sonucu çıkarılabilir.

Tablo 2. As(V)'ın DOKIP sorbenti üzerine adsorpsiyonunda Langmuir, Freundlich ve D-R izotermlerine ait sabitlerin değerleri

\begin{tabular}{lccc} 
degerleri & \multicolumn{3}{c}{ Sabit Değerler } \\
\hline İzoterm & $\mathbf{R}^{2}$ & \multicolumn{2}{c}{} \\
\hline Langmuir & 0,998 & $\mathrm{Q}_{\max }(\mathrm{mg} / \mathrm{g})$ & 4,74 \\
\cline { 3 - 4 } & & $\mathrm{K}_{\mathrm{L}}(\mathrm{L} / \mathrm{mg})$ & 3,98 \\
\hline Freundlich & 0,922 & $\mathrm{~K}_{\mathrm{f}}(\mathrm{mg} / \mathrm{g})$ & 3,01 \\
\cline { 3 - 4 } & & $1 / \mathrm{n}$ & 0,45 \\
\hline D-R & 0,831 & $\mathrm{X}_{\mathrm{m}}(\mathrm{mg} / \mathrm{g})$ & 5,90 \\
\cline { 3 - 4 } & & $\mathrm{E}(\mathrm{kJ} / \mathrm{mol})$ & 0,11 \\
\hline
\end{tabular}

\subsection{DOKIP ile As(V) adsorpsiyonunun literatür karşılaştırması}

Çalışmamızda As(V) giderimi için kullanmış olduğumuz adsorbente benzer malzemeler ile yapılmış olan çalışmalarda elde edilen optimum $\mathrm{pH}$ değeri ve As(V) iyonları için adsorplama kapasitesine ilişkin literatür çalışmaları Tablo 3'de verilmiştir. Tabloda verilen adsorbentlerin $\mathrm{As}(\mathrm{V})$ adsorplama kapasiteleri $\left(\mathrm{Q}_{\max }, \mathrm{mg} / \mathrm{g}\right)$ karşılaştırıldığında DOKIP adsorbenti için elde edilen adsorplama kapasitesinin anlamlı olduğu tespit edilmiştir.

Tablo 3. As(V) gideriminde kullanılan bazı düşük maliyetli adsorbentler için optimum pH ve maksimum adsorpsiyon kapasitesi (Qmax, mg/g) karşılaştırılması

\begin{tabular}{cccc}
\hline Adsorbent & $\mathbf{p H}$ & $\mathbf{Q}_{\mathbf{m a x}}(\mathbf{m g} / \mathbf{g})$ & Kaynak \\
\hline Feldspar & 3 & 0,24 & {$[33]$} \\
\hline $\begin{array}{c}\text { Magnetik demir oksit } \\
\text { kaplı kum nanopartikülü }\end{array}$ & 7 & 0,29 & {$[34]$} \\
\hline $\begin{array}{c}\text { Fe(III)-Sn(IV) karışı ile } \\
\text { kaplanmıș kum }\end{array}$ & 7 & 0,23 & {$[35]$} \\
\hline Demir oksit kaplı kum & & 0,021 & {$[36]$} \\
\hline Mangan oksit kaplı zeolit & 7 & 0,15 & {$[37]$} \\
\hline Modifiye Zeolit Y & 6 & 1,34 & {$[38]$} \\
\hline Seryum yüklü pomza & 7 & 0,893 & {$[39]$} \\
\hline MnO kaplı pirinç kabuğu & 3 & 10,0 & {$[40]$} \\
\hline $\begin{array}{c}\text { Demir oksit kaplı mantar } \\
\text { biokütlesi }\end{array}$ & 6 & 1,08 & {$[41]$} \\
\hline DOKIP & 3 & 1,92 & $\begin{array}{c}\text { Bu } \\
\text { çalıșma }\end{array}$
\end{tabular}




\section{Tartışma ve Sonuç}

$\mathrm{Bu}$ çalışmada sulu ortamda bulunan As(V) iyonlarının giderimi amacıyla batch yöntemine dayalı katı faz ekstraksiyonu yöntemi kullanılmıştır. Sulu çözeltiden As(V) giderilmesi için uygun bir katı sorbent olabileceği düşünülen <63 $\mu$ m partikül büyüklüğüne sahip demir oksit kaplı Isparta pomzası adsorbentleri elde edilmiştir. Modifiye edilmemiş olan HIP ve demir oksit kapl, DOKIP sorbentlerinin yapıları FTIR, XRD, BET yüzey analizi ve SEM görüntüleme teknikleri kullanılarak aydınlatılmıștır. HIP ve DOKIP sorbentleri için sulu çözeltilerden $\mathrm{As}(\mathrm{V})$ iyonlarının adsorpsiyonunu etkileyen çözelti $\mathrm{pH}^{\prime} \mathrm{l}$, çözeltideki başlangıç As (V) konsantrasyonu, temas süresi, adsorbent dozu ve sıcaklık parametreleri ile değiştiği gözlenmiştir.

$\mathrm{As}(\mathrm{V})$ gideriminde, çözeltinin başlangıç $\mathrm{pH}$ değerinin etkisi 2,0-9,0 arasında değișen $\mathrm{pH}$ değerlerinde incelenmiş ve optimum $\mathrm{pH}$ değerleri olarak HIP ve DOKIP için sirasıyla $\mathrm{pH} 4,0$ ve 3,0 olarak elde edilmiştir. Başlangıç As(V) konsantrasyonunun adsorpsiyon sürecinde etkisi için 0,2-8,0 mg/L aralığında çalışılmış ve gerçek örneklerde mevcut As(V) konsantrasyonlarının düşük olması nedeniyle HIP ve DOKIP katı sorbentleri için en yüksek adsorpsiyon verimlerine sahip oldukları $1 \mathrm{mg} / \mathrm{L}$ optimum başlangıç As(V) konsantrasyonu olarak alınmıştır. Katı sorbentler üzerine As(V) adsorpsiyonunda temas süresinin etkisi 5-240 dakika aralığında incelenmiş, HIP ve DOKIP katı sorbentleri için adsorpsiyon dengesinin tam olarak kurulduğu sirasıly 15 ve 30 dakika optimum temas süresi olarak belirlenmiștir. As(V) adsorpsiyonunda adsorbent dozu (g/L) oranı As(V) çözelti hacmi 25 mL olarak sabit tutularak farklı miktarlarda sorbent alınarak incelenmiştir. Optimum adsorbent dozu oranları HIP ve DOKIP katı sorbenti için sırasıyla 2,0 ve $0,5 \mathrm{~g} / \mathrm{L}$ olarak belirlenmiştir. As(V) adsorpsiyonuna sıcaklığın etkisi $25-55^{\circ} \mathrm{C}$ aralığında incelenmiş, HIP ve DOKIP katı sorbentleri için optimum çalışma sıcaklığı $25^{\circ} \mathrm{C}$ olarak belirlenmiştir. DOKIP katı sorbenti ile As(V) adsorpsiyonunun ekzotermik karakterli olduğu saptanmıștır. Optimum şartlarda As(V) gideriminde en yüksek adsorpsiyon kapasitesine sahip olan DOKIP sorbenti için \%Ads. ve

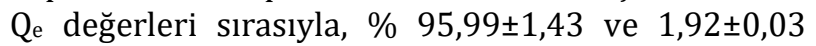
$\mathrm{mg} / \mathrm{g}$ olarak elde edilmiştir.

As(V)'in DOKIP katı sorbenti üzerine adsorpsiyonunda, $\Delta \mathrm{H}, \Delta \mathrm{G}$ ve $\Delta \mathrm{S}$ termodinamik parametreleri sirasiyla (-)0,078 kJ/mol.K, (+)54,0 $\mathrm{kJ} / \mathrm{mol}$ ve (-) $0,173 \mathrm{~kJ} / \mathrm{mol}$.K olarak elde edilmiştir. Adsorpsiyon $\Delta \mathrm{H}$ değerinin negatif olması As(V) iyonlarının DOKIP-1 katı sorbentine adsorpsiyonunun fiziksel adsorpsiyon ve ekzotermik karakterli olduğunu göstermektedir. As(V) adsorpsiyon $\Delta \mathrm{S}$ değişim değerlerinin negatif olması ise, adsorpsiyon prosesi sırasında katı/çözelti ara yüzeyinde hedef kirletici iyonlarının adsorpsiyonu sonucu moleküler harekette azalma ile ilişkilendirilebilmektedir. Sulu çözeltiden As(V) iyonlarının DOKIP üzerine adsorpsiyonu Freundlich ve $\mathrm{D}-\mathrm{R}$ izotermlerine daha düşük oranlarda uyum gösterirken, Langmuir izotermine daha uygun olduğu gözlenmiştir. Langmuir izoterminden bulunan teorik kapasite değeri 4,74 mg As (V)/g DOKIP katı sorbenti olarak elde edilmiştir.

Elde edilen sonuçlara göre, Isparta pomzası kullanılarak literatüre $[12,13,14]$ göre elde edilen DOKIP katı sorbenti ilk defa bu çalışmada sulu çözeltilerden As(V) adsorpsiyonu için kullanılmış düşük maliyetli, adsorpsiyon verimi yüksek, geri kazanımın kolay ve verimin yüksek olması nedeniyle adsorbentin kullanılabilirliğinin uygun olduğu belirlenmiștir. Optimize edilen yöntem sulu çözeltilerden $\mathrm{As}(\mathrm{V})$ gideriminde ve arıtılmasında, potansiyel alternatif bir sorbent olarak kullanılabilecektir.

\section{Teşekkür}

$\mathrm{Bu}$ çalıșmaya, 4804-YL1-16 Nolu proje ile maddi destek sağlayan Süleyman Demirel Üniversitesi, Bilimsel Araştırma Projeleri Koordinasyon Birimi'ne teşekkür ederiz.

\section{Kaynakça}

[1] Monique, B., Fritz, H.F., 2003. Arsenic - a Review. Part I: Occurrence, Toxicity, Speciation, Mobility. Acta Hydrochimica et Hydrobiologica, 311(2003), 9-189.

[2] Mohan, D., Pittman, C.U., 2007. Review Arsenic removal from water/wastewater using adsorbents-A critical review. Journal of Hazardous Materials, 142(2007), 1-53.

[3] Smedley, P.L., Kinniburgh, D.G., 2002. A review of the source, behaviour and distribution of arsenic in natural waters. Applied Geochemistry 17(2002), 517-568.

[4] Choong, T.S.Y., Chuah, T.G., Robiah, Y., Koay, F.L.G., Azni, I., 2007. Arsenic Toxicity, health hazards and removal techniques from water: an overview. Desalination, 217(2007), 139-166.

[5] Bhattacharya, P., Mukherjee, A.B., Bundshuh, J., Zevenhoven, R., Loeppert, R.H., 2007. Arsenic in Soil and Groundwater Environment. Volume 9, Elsevier.

[6] Jain, C.K., Singh, R.D., 2012. Technological options for the removal of arsenic with special reference to South East Asia. Journal of Environmental Management, 107(2012), 1-18.

[7] Song, S., Valdivieso, A.L., Campos, D.J.H., Peng, C., Fernandez, M.G.M., Soto, I.R., 2006. Arsenic removal from high-arsenic water by enhanced coagulation with ferric ions and coarse calcite. Water Research, 40(2006), 364-372. 
[8] Malik, A.H., Khan, Z.M., Mahmood, Q., Nasreen, S., Bhatti, Z.A., 2009. Perspectives of low cost arsenic remediation of drinking water in Pakistan and other countries. Journal of Hazardous Materials, 168(2009), 1-12.

[9] Wang, S., Zhao, X., 2009. On the potential of biological treatment for arsenic contaminated soils and groundwater. Journal of Environmental Management, 90(2009), 2367-2376.

[10] Sharma, V.K., Sohn, M., 2009. Aquatic arsenic: Toxicity, speciation, transformations, and remediation. Environment International, 35(2009), 743-759.

[11] Pokhrel, D., Viraraghavan, T., 2006. Arsenic removal from an aqueous solution by a modified fungal biomass. Water Research, 40(2006), 549552.

[12] Lai, C.H., Lo, S.L., Chiang, H.L., 2000. Adsorption/desorption properties of copper ions on the surface of iron-coated sand using BET and EDAX analyses. Chemosphere 41(2000), 1249-1255.

[13] Lai, C.H., Chen, C.Y., 2001. Removal of metal ions and humic acid from water by iron-coated filter media. Chemosphere 44(2001), 1177-1184.

[14] Bekaroğlu, Ş.Ş.K. 2010. Yüzeyleri Modifiye Olmuş Çeşitli Adsorbanlarla Doğal Organik Madde Giderimi. Süleyman Demirel Üniversitesi,Fen Bilimleri Enstitüsü, Doktora Tezi, 284s, Isparta.

[15] Funing, L., Daren C., $1982 . \quad$ Rapid spectrophotometric determination of arsenic and phosphorus after development of molybdenum blue complex at room temperature. Analytical Abstracts, 42(1982), 130.

[16] Far, L.B., Souri, B., Heidari, M., Khoshnavazi, R., 2012. Evaluation Of Iron And Manganese-Coated Pumice Application For The Removal of As(V) From Aqueous Solutions. Iranian Journal of Environmental Health Science \& Engineering, 9(2012), 1-9.

[17] Oztel, M.D., Akbal, F., Altas, L., 2015. Arsenite Removal By Adsorption Onto İron Oxide-Coated Pumice And Sepiolite. Environmental Earth Sciences, 73(8)(2015), 4461-4471.

[18] Chang, Y., Li, C. W., Benjamin, M. M., 1997. Iron oxide-coated media for NOM sorption and particulate filtration. Journal of the American Water Works Association, 89 (5)(1997), 100113.

[19] Indah, S., Helard, D., 2017. Evaluation Of İron And Manganese-Coated Pumice From Sungai Pasak, West Sumatera, Indonesia For The Removal Of Fe (II) And Mn (II) From Aqueous
Solutions. Procedia Environmental Sciences, 37(2017), 556-563.

[20] Boddu, V. M., Abburi, K., Talbott, J.L., Smith, E.D., Haasch, R. 2008. Removal of arsenic (III) and arsenic (V) from aqueous medium using chitosan-coated biosorbent. Water Research, 42 (3)(2008), 633-642.

[21] Ranjan, D., Talat M. ve Hasan, S.H., 2009. Biosorption of Arsenic from Aqueous Solution Using Agricultural Residue 'Rice Polish'. Journal of Hazardous Materials, 166(2009), 1050-1059.

[22] Natale, F.D., Erto, A., Lancia, A., Musmarra, D., 2008. Experimental and Modelling Analysis of As(V) Ions Adsorption on Granular Activated Carbon. Water Research, 42(2008), 2007-2016.

[23] Chen, W., Parette, R., Zou,J., Cannon, F.S. ve Dempsey, B.A., 2007. Arsenic Removal by IronModified Activated Carbon. Water Research, 41(2007), 1851-1858.

[24] Wang, X., Liu, Y., Zheng, J., 2016. Removal of As(III) and As(V) from water by chitosan and chitosan derivatives: a review. Environmental Science Pollution Research, 23(2016), 1378913801.

[25] Sarı, A., Mendil, D., Tuzen, M., Soylak, M. 2008. Biosorption of $\mathrm{Cd}(\mathrm{II})$ and $\mathrm{Cr}$ (III) From Aqueous Solution by Moss (Hylocomium splendens) Biomass: Equilibrium, Kinetic and Thermodynamic Studies. Chemical Engineering Journal, 144(2008), 1-9.

[26] Karaoglu, H.M., Zor, Ş., Ugurlu, M., 2010. Biosorption of $\mathrm{Cr}$ (III) from solutions using vineyard pruning waste. Chemical Engineering Journal, 159(2010), 98-106.

[27] Gupta, V.K., Rastogi, A., Nayak, A. 2010. Adsorption Studies on the Removal of Hexavalent Chromium From aqueous Solution Using a Low Cost Fertilizer Ġndustry Waste Material. The Journal of Colloid and Interface Science, 342(2010), 135-141.

[28] Langmuir, I., 1918. The adsorption of gases on plane surfaces of glass, mica and platinium. Journal of American Chemical Society, 40, 13611403.

[29] Freundlich, H.M.F., 1906. Über die adsorption in lösungen. Zeitschrift für Physikalische Chemie (Leipzig) 57A, 385-470.

[30] Dubinin, M.M., Zaverina, E.D., Radushkevich, L.V., 1947. Sorption and structure of active carbons. I. Adsorption of organic vapors, Zhurnal Fizicheskoi Khimii. 21, 1351-1362.

[31] Helfferich, F., 1962. Ion Exchange, McGraw Hill, New York, USA, p. 166.

[32] Sawalha, M.F., Videa, J.R.P., Gonzalez, J.R., Gardea-Torresdey, J.L., 2006. Biosorption of 
Cd(II), Cr(III), and Cr(VI) by saltbush (Atriplex canescens) biomass: thermodynamic and isotherm studies. Journal of Colloid and Interface Science, 300, 100-104.

[33] Yazdani, M., Tuudjarvi, T., Bhatnagar, A., Vahala, R., 2016. Adsorptive removal of arsenic (V) from aqueous phase by feldspars: Kinetics, mechanism, and thermodynamic aspects of adsorption. Journal of Molecular Liquids, 214(2016), 149-156.

[34] Afzali, D., Rouhani, M., Fathirad, F., Shamspur, T., Mostafavi, A., 2016. Nano-iron Oxide Coated On Sand As A New Sorbent For Removal Of Arsenic From Drinking Water. Desalination and Water Treatment, 57(2016), 13030-13037.

[35] Chaudhry, S.A., Ahmed, M., Siddiqui, S.I., Ahmed, S., 2016. Fe (III)-Sn (IV) Mixed Binary Oxidecoated Sand Preparation and Its Use for the Removal of As (III) and As (V) from Water: Application of Isotherm, Kinetic and Thermodynamics. Journal of Molecular Liquids, 224(2016), 431-441.

[36] Hsu, J.C., Lin, C.J., Liao, C.H., Chen, S.T., 2008. Removal of As (V) and As (III) by Reclaimed Iron-oxide Coated Sands. Journal of Hazardous Materials, 153(2016), 817-826.

[37] Massoudinejad, M., Asadi, A., Vosoughi, M.,
Gholami, M., Karami, M.A.A, 2015 Comprehensive Study (Kinetic, Thermodynamic And Equilibrium) of Arsenic (V) Adsorption Using $\mathrm{KMnO} 4$ Modified Clinoptilolite. Korean Journal of Chemical Engineering, 32(2015), 2078-2086.

[38] Yusof, A.M., Malek, N., 2009. Removal of Cr (VI) and As (V) From Aqueous Solutions By HDTMAModified Zeolite Y. Journal of Hazardous Materials, 162(2009), 1019-1024.

[39] Asere, T.G., Verbeken, K., Tessema, D.A., Fufa, F., Stevens, C.V., Du Laing, G. 2017. Adsorption of As(III) versus As(V) from aqueous solutions by cerium-loaded volcanic rocks. Environmental Science and Pollution Research, 24(25)(2017), 20446-20458.

[40] Ouédraogo, I.W.K., Pehlivan, E., Tran, H.T., Paré, S., BonziCoulibaly, Y.L., Zachmann, D., Bahadir, M., 2016. Removal Of Arsenic (V) From Aqueous Medium Using Manganese Oxide Coated Lignocellulose/Silica Adsorbents. Toxicological and Environmental Chemistry, 98(2016), 736747.

[41] Pokhrel, D., Viraraghavan, T., 2008. Arsenic Removal from an Aqueous Solution by Modified A. Niger Biomass: Batch Kinetic and Isotherm Studies. Journal of Hazardous Materials, 150(2008), 818-825. 